\title{
SURGERY FOR ADULT SPINAL SCOLIOSIS: DO THE BENEFITS OUTWEIGH THE RISKS?
}

\author{
CIRURGIA EM ADULTOS COM ESCOLIOSE: OS BENEFÍCIOS SÃO MAIORES QUE \\ OS RISCOS?
}

\author{
CIRUGÍA PARA LA ESCOLIOSIS ESPINAL EN ADULTOS: ¿LOS BENEFICIOS SON \\ SUPERIORES A LOS RIESGOS?
}

Jeferson Dedéa, ${ }^{1}$ Alisson Roberto Teles, ${ }^{2}$ Asdrubal Falavigna ${ }^{3}$

1. Universidade de Caxias do Sul - UCS, Laboratory for Clinical Studies and Basic Models in Spinal Cord Pathologies, Caxias do Sul, RS, Brazil.

2. McGill University - UMG, Neurosurgery Department, Montreal, QC, Canada.

3. Universidade de Caxias do Sul - UCS, Postgraduate Program in Health Sciences, Caxias do Sul, RS, Brazil.

\begin{abstract}
Around $6 \%$ of the elderly population over 65 years of age are affected by adult spinal deformity (ASD). The increasing prevalence of ASD with aging has prompted discussion regarding the use of various techniques for its treatment, such as surgery and conservative treatment. The objective of this study is to investigate whether surgical treatment demonstrates significant benefits as compared to conservative treatment. A literature review was conducted, focusing on the most relevant papers on the topic published in the last five years. Surgical treatment, which costs an average of US\$99,114 per procedure, enables almost instant improvement of the pain and disability of ASD. The rate of perioperative complications in ASD is approximately 7.5\%, and the average improvement in back pain is 6.2 times higher in the surgical approach than in conservative treatment. In addition, the use of modern operative techniques, such as minimally invasive surgery (MIS), reduces the complications and greatly improves patients' quality of life, compared to open surgery. Therefore, the expected benefits of surgical treatment meets the patient's expectations by eliminating the pain caused by ASD. Although surgical treatment has a higher cost and a greater risk of complications, the use of minimally invasive techniques give the ASD patient a better quality of life. Level of evidence III; Non-Systematic Review.
\end{abstract}

Keywords: Spinal Diseases; Treatment; Costs and Cost Analysis; Quality of Life; Surgery; Conservative Treatment.

\section{RESUMO}

Adultos com deformidade na coluna (ASD) representam cerca de 6\% da população idosa com mais de 65 anos de idade. Assim, a crescente prevalência da doença com o envelhecimento leva à uma discussão sobre o uso de várias técnicas para tratar ASD, como cirurgia e tratamento conservador. O objetivo deste estudo é verificar se os benefícios do tratamento cirúrgico mostram melhora significativa em relação ao tratamento conservador. Foi realizada uma revisão da literatura dos trabalhos mais relevantes dos últimos 5 anos, que eram pertinentes ao tema do presente estudo. Com um custo médio de US\$ 99,114 por procedimento, o tratamento cirúrgico permite a melhora instantânea da dor e da incapacidade causada aos ASD e apresenta uma taxa de complicações perioperatórias de aproximadamente 7.5\% . A média de melhora na dor nas costas é 6.2 vezes maior na abordagem cirúrgica do que o apresentado pelo tratamento conservador. Além disso, o uso de modernas técnicas operatórias, como a cirurgia minimamente invasiva (MIS), que permite a diminuição das complicações e uma melhora muito superior na qualidade de vida, diferentemente da cirurgia aberta. Assim, o ganho esperado com o tratamento cirúrgico atende as expectativas do paciente ao eliminar o processo doloroso nos ASD. A escolha pelo tratamento cirúrgico, apesar de apresentar um custo mais elevado e um maior risco de complicações, e o uso de técnicas minimamente invasivas, permitem ao paciente ASD uma melhor qualidade de vida. Nível de evidência III; Revisão não Sistemática.

Descritores: Doenças da Coluna Vertebral; Tratamento; Custos e Análise de Custo; Qualidade de Vida; Cirurgia; Tratamento Conservador.

\section{RESUMEN}

Alrededor del $6 \%$ de las personas mayores de 65 años de edad se ven afectadas por la deformidad espinal adulta (DEA). La creciente prevalencia de DEA con el envejecimiento ha impulsado la discusión sobre el uso de diversas técnicas para su tratamiento, como la cirugía y el tratamiento conservador. El objetivo de este estudio es investigar si el tratamiento quirúrgico demuestra beneficios significativos en comparación con el tratamiento consenvador. Una revisión de la literatura, centrada en los artículos más relevantes se llevó a cabo en los últimos cinco años. Con un costo promedio de US\$ 99.114, el tratamiento quirúrgico permite una mejora casi instantánea del dolor y la discapacidad de de DEA. La tasa de complicaciones perioperatorias la DEA es aproximadamente del 7,5\% y la mejoría promedio en el dolor de espalda es 6,2 veces mayor en el tratamiento quirúrgico que en el tratamiento conservador. Además, el uso de técnicas quirúrgicas modernas, como cirugía mínimamente invasiva (CMI) reduce las complicaciones y mejora en gran medida la calidad de vida de los pacientes en comparación con la cirugía abierta. Por lo tanto, los beneficios esperados del tratamiento quirúrgico cumplen con las expectativas del paciente al eliminar el dolor causado por la DEA. Aunque el tratamiento quirúrgico tiene un costo más elevado y un mayor riesgo de complicaciones, el uso de técnicas mínimamente invasivas permite que el paciente con DEA tenga una mejor calidad de vida. Nivel de evidencia III; Revisión no Sistemática.

Descriptores: Enfermedades de la Columna Vertebral; Tratamiento; Costos y Análisis de Costo; Calidad de Vida; Cirugía; Tratamiento Conservador.

Work conducted at Universidade de Caxias do Sul, RS, Brazil.

Correspondence: Asdrubal Falavigna. Rua General Arcy da Rocha Nóbrega, 401/602, Caxias do Sul, RS, Brasil. 95040-290. asdrubalmd@gmail.com 


\section{INTRODUCTION}

With global population aging, there has been an increase in age-related spinal disorders. It is estimated that by 2050, there will be about 379 million people aged over 80 , as compared to 69 million in 2000. ${ }^{1}$ But this greater longevity is also resulting in a higher incidence of chronic diseases. In adult spinal deformity (ASD) patients, the aging spine undergoes a degenerative process, with symptoms ranging from severe pain to lack of capacity for persistent movement, as well as confusion and functional loss. ${ }^{2}$ ASD therefore impacts on quality of life. The mean age at which the incidence of ASD begins to increase is 50.4 years, placing it at the same level as other chronic diseases, such as cancer.

The prevalence of ASD in the North American population aged over 65 increased from 12.5 million (10\%) in 1990 to 47.7 million (15\%) in 2015 , and this figure is expected to increase to 91.5 million (23\%) by $2060 .^{3}$ Another point to look at in this In this context, surgical intervention has doubled in the last decade, according to the US Nationwide Inpatient Sample database. The cost of treatment is considered high; an estimated annual US\$80.3 billion, which is comparable to the US\$89 billion spent on the treatment of cancer. ${ }^{4}$

The prevalence of ASD in adults over 50 years of age is approximately $6 \%$. Treatment is initially conservative, but the effectiveness of such methods is not fully understood in the literature. Once extensive attempts at conservative treatments have failed, surgery is used, aiming to decompress neural elements and restore sagittal and coronal balance, with more predictable outcomes. ${ }^{5}$ This study is a review of the literature published in the last few years that shows the marked benefits of surgical treatment for ASD over conservative treatment.

\section{METHODS}

This is a non-systematic review of the literature published in the last five years, using the PubMed database and the search terms spinal deformity, treatment, cost, quality of life, surgery, conservative technique. We analyzed prospective and retrospective clinical studies with full text, in English, published between January 2012 and September 2016. At the end of the analysis, 49 articles were identified as the most relevant studies for the proposed objective.

\section{RESULTS}

The literature review found that non-surgical treatment had a lower cost (US\$9,704) than surgical treatment (US\$42,383). However, surgical treatment presented better performance in terms of remission of pain after two years of follow-up (73.2\%). The rates of complications varied from $9.52 \%$ to $81.52 \%$. Minimally invasive surgery in adult deformity had lower complication rates when compared to the open approach (22.9\% vs. $41.2 \%)$. The costs of surgery for adult scoliosis has increased from US\$103,143 to US\$126,323 in the last five years. The population has increased by $20 \%$ over a 10 -year period. Decision-making on adult spine deformity has become more complex, not only because of the costs and rates of complications, but also due to the presence of some degree of spinal deformity in approximately $68 \%$ of the population aged over 60 years.

\section{DISCUSSION}

Spinal surgery for ASD provides the patient with considerable gains in quality of life. On the other hand, the costs of surgery are high. Thus, the treatment options for patients with spinal deformities may include surgical and/or conservative treatment, depending on the degree of spinal deformity. However, like any invasive procedure, the surgery can lead to complications. Modern techniques have been developed to reduce the impact of open surgery. These include minimally invasive surgery (MIS), which proposes lower rates of complications combined with a shorter recovery time. Although MIS presents considerable benefits, the decision between treatment options should take into account the improvements in patients' quality of life, bearing in mind that the choice between surgical and conservative treatment entails different costs and different benefits. Comparative-Effectiveness: Surgery versus Conservative Care

In the last decade, the cost of treating spinal deformities has increased. Over a 2-year period, the estimated cost of non-surgical treatment ranged from US\$9,704 in symptomatic patients to US\$14,022 in incapacitated patients. An overview of conservative treatment estimates that approximately $30 \%$ of patients reported pain relief after 2 years of nonoperative care, while $50 \%$ of those who had not reported pain previously began, after 2 years, to notice the recurrence of pain, and $27 \%$ of patients presented a new onset of pain during this same period. Teles et al. ${ }^{6}$ show that there is a better effect size of surgery compared to conservative treatment, with greater benefits. (Figure 1) In contrast to surgical treatment for ASD, patients had a 6.4-fold improvement in back pain, and an approximately 3.0-fold improvement in leg pain. ${ }^{7}$ This differs from the results for ASD patients who have undergone conservative treatment and continued to have back and leg pain, or in whom the pain even became worse. In addition, in order to distinguish between the best and worst outcomes of surgical treatment, the patient's state of mental health should be evaluated, because around $25 \%$ of patients are also diagnosed with a depressive condition that can impact on the preparation for surgery. Depression is associated with a higher rate of complications, since repeated failures of conservative treatment generally lead to reduced quality of life for the patient. ${ }^{8}$

Although surgical costs were higher, ranging from an average of US $\$ 42,383$ to US $\$ 217,717$, and an average operating time of 410.71 minutes, ranging from 327 minutes to 504 minutes, the average loss of estimated quality of life achieved with this treatment method was high. Traditionally, a cost of US\$100,000/QALY (quality-adjusted life year) was widely accepted for this effective intervention. ${ }^{9}$ The number of patients who achieved positive results from surgery had increased from $41 \%$ to $73.2 \%$ in the period from 2008 to 2013. Patients with ASD demonstrated a more substantial gain in quality of life following surgical treatment, whereas conservative treatment generally did not improve the pain or levels of disability. ${ }^{10}$ One technique that clearly demonstrated increased efficacy of the surgical approach in ASD patients was minimally invasive surgery (MIS). The most frequent uses of MIS in spinal surgery are to reduce intraoperative complications, compared to the open technique, and to present better clinical results. ${ }^{11}$ In order to ensure consistent improvement after surgical treatment, the use of the Core Outcome Measures Index for the back (COMl-back) is recommended as an instrument for evaluating the results. Using this instrument, the evaluation of recurrence of the main problems, such as pain, disability, loss of function and loss of quality of life, showed a significant difference between the two types of treatment, demonstrating that surgical treatment brings great benefits for ASD patients. ${ }^{12}$

\section{Complications}

The forecast US population growth for the period 2010 to 2050 will inevitably lead to an increase in the prevalence of ASD. This, in turn, will result in an increase in surgical treatment. It is estimated

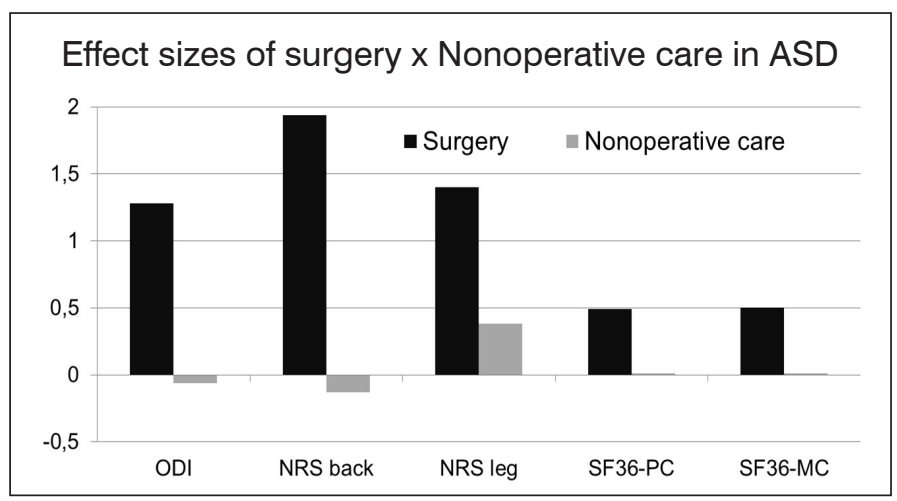

Figure 1. Effect size of surgery and nonoperative care in different health-related quality of life measures for adult spinal deformity. 
that the complications resulting from this procedure range from $13.8 \%$ to $41 \% .{ }^{13}$ Thus, readmissions of patients due to complications generate a high cost, estimated at US $\$ 41$ billion, compared with other surgical specialties. The risks of readmission are associated with the perioperative period, with an estimated readmission rate of $7.5 \%$ in ASD patients. ${ }^{14}$ Teles et al. ${ }^{6}$ demonstrated a wide variation in complication rates, ranging from $9.52 \%$ to $81.52 \%$. (Figure 2 )

Spinal surgery presented a rate of complications of $41.2 \%$. Of these, about $16.5 \%$ required revision surgery, with $15 \%$ occurring within six weeks, $38 \%$ between six weeks to one year, and $48 \%$ between one and two years. The surgical reassessment rate ranged from $10 \%$ to $25 \%$. Moreover, after revision surgery, it was estimated that $17.5 \%$ of patients had an infection. ${ }^{15}$ The most common complications found after surgical treatment of ASD were malposition of the screw, neurological deficit, cardiopulmonary problems, and infections, which together made up about $88 \%$ of all types of adverse events caused by this kind of approach. ${ }^{16}$ Depending on the complexity of the surgical procedure, there was an increased risk of infection that can lead to a further stay of between one to 3.8 days in the ICU. Likewise, infections resulting from orthopedic procedures to correct this pathology resulted in increased ICU stay rates of up to 9.5 days, at an increased cost of US\$15,129 per admission. ${ }^{17}$

The most common type of complication was related to the screw implantation, with surgical reintervention rates ranging from $31.7 \%$ to $52.6 \%$. Another common adverse event was stem rupture, with $47 \%$. In the radiographic findings, proximal junction kyphosis (PJK) was the most frequent incident comorbidity (54.5\%), followed by pseudoarthrosis (11.4\%). In addition, the incidence of complications may be higher in patients submitted to a previous intervention $(53.3 \%)$ than in those who have never undergone any invasive procedure (37.9\%)..$^{18}$ Another factor that may influence complications is age, with patients older than 60 years presenting a $50 \%$ risk of complications. A mortality rate of $0.85 \%$ was reported, predominantly among the elderly population. ${ }^{19}$ The average risk for new operations performed within 6 years of the first surgery was 44\%, and 1 in 4 patients have a higher risk of requiring a new procedure within 2 years after the first surgery. The overall survival rate of elderly patients undergoing surgical treatment was $78 \%$ at 12 months, $74 \%$ at 24 months, $71 \%$ at 36 months and $56 \%$ at 70 months. ${ }^{20}$

Although ASD surgery is complex and involves risks, it is able to restore neurological function in patients with neurological deficit. ${ }^{21}$ In one study, the incidence of neurological complications was $17.6 \%$.
Of these, neurological complications of surgery were estimated at $13.7 \%$, compared to $5 \%$ in patients treated conservatively. The most common complications were radiculopathy (30\%), motor deficit $(22 \%)$, changes in mental status (12\%), and sensory deficit (12\%). Revisions and interbody mergers were associated with an increased risk of neurological complications, while decompression and osteotomy did not increase the risk of neurological complications. ${ }^{22}$ The most commonly used pathway were posterior to the thoracic and lumbar spine, but often, the most common approach routes were anterior and lateral, which are usually associated with complications of the femoral nerve and lumbar plexus. Patient selection, surgical technique, and intraoperative neuronal monitoring reduced the incidence of complications and optimized the outcomes. ${ }^{23}$

\section{The Role of Minimally Invasive Surgery in Adult Scoliosis}

MIS is a spinal surgery technique that is at the forefront of innovations. Not only is this intervention performed through a smaller incision, but it also reduces the morbidity associated with traditional open surgery. Correction of ASD using this new approach reduces postoperative risks and consequently, recovery time. Thus, the benefits of MIS make it much more attractive for both patient and surgeon. ${ }^{24}$ This MIS technique can be performed alone or in combination, and each category can be classified according to the degree of invasiveness. The categories include MIS decompression, circumferential MIS (cMIS) and MIS + open surgery (hybrid). The MIS technique reduces blood loss and allows earlier mobilization compared to open surgery. The main complications of MIS are pulmonary embolism, myocardial infarction, and new neurological deficits. ${ }^{25}$

The postoperative recovery period after MIS is much shorter, making it more suitable for elderly patients. The MCID (minimal clinically important difference) suggests that MIS benefits elderly people with ASD. ${ }^{26}$ Comparison between open versus minimally invasive surgery depends on the best results obtained. In open surgery, the improvement is 36 points (on a decreasing scale of 43 to 7 ), while for minimally invasive surgery, the improvement is 46 points (on a scale of 58 to 12). These data allow the surgeon to choose the technique to be used. ${ }^{27}$ In this aspect, ASD surgery is associated with a significant risk of complications, confronting both types of surgical approach to cMIC and Hybrid (HYB). cMIC presented few cases with complications because the technique is less invasive. In contrast, HYB had an average of 1.6 more comorbidities than $\mathrm{CMIC} .^{28}$

ASD is associated with lumbar disc degeneration, leading to

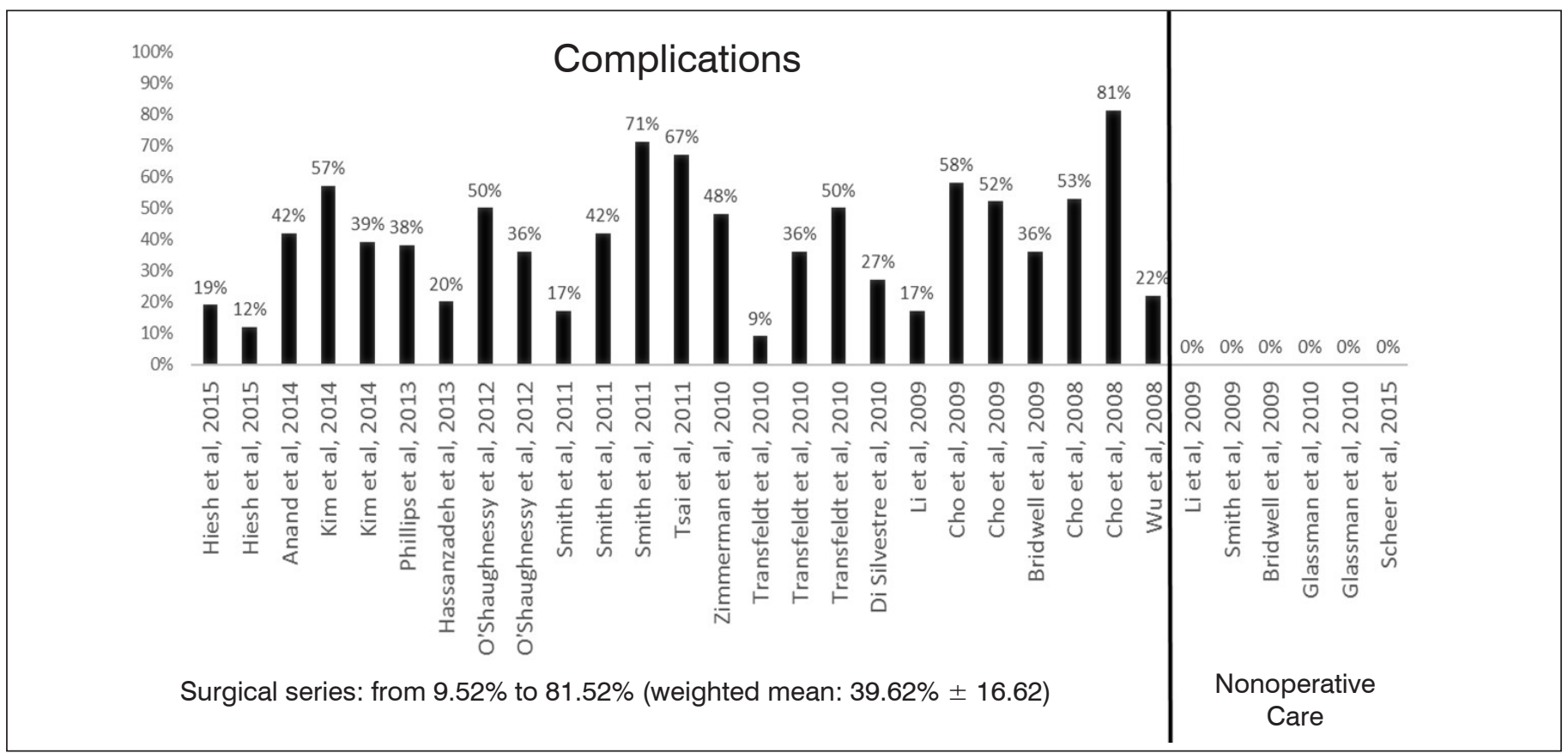

Figure 2. Complication Rates in ASD 
misalignment in the sagittal plane, the coronal plane, or often a combination of both. Patients undergoing MIS have a low hospitalization cost and a shorter hospitalization time, with greater durability and effectiveness. However, there is resistance to the use of another technique used in the surgical treatment of ASD: lateral interbody fusion (LIF) combined with posterior opening (OP). LIF + OP surgery has a moderately severe strategic effect on ASD, but presents a higher implant cost. However the advantages of HYB are superior to LIF + OP, with faster recovery and greater relief of back pain and disability. ${ }^{29}$ Another problem associated with ASD patients is PJK, which is treated as one of the main potential complications. Comparing CMIS and HYB, it was found that the rate of PJK and reoperation due to PJK was lower using CMIS than HYB. MIS therefore reduces the damage caused by the placement of the screws, since it is a less invasive technique. ${ }^{30}$

Extreme lateral interface fusion (XLIF) is a new technique designed to ensure greater safety, as well as having a better outcome in octogenarian patients. A classification was proposed to help choose the surgical strategy for the use of XLIF in adults with scoliosis. The classification corresponds to the degree of deformity, type I being used for nerve decompression, type II for disk limitation, type III for severe coronal deformity, and type IV for sagittal disequilibrium. ${ }^{31}$ Minimally invasive spinal deformity surgery (MISDEF) is an algorithm that allows the surgeon to make a rational choice between open surgery or MIS. It is divided into three classes. Class I is used for MIS decompression surgery. In Class II MIS, surgery is used for decompression and interbody fusion. Class III is used for open surgery with more or less extensive thoracic spinal fusion osteotomy. ${ }^{32}$ The results of using the XLIF technique showed 93\% short-term pain relief, and $95 \%$ of the patients returned to normal activities within an average of 8.4 months. In the long term (4.7 years), the satisfaction level was $75 \%$, with $64 \%$ of patients achieving pain relief and $56 \%$ returning to their normal activities. These results suggest that the XLIF technique is a feasible option for the treatment of ASD patients, and should be taken into account by the surgeon. ${ }^{33}$

MIS has relatively few complications, with an estimated average complication rate of $22.9 \%$. This is considered low compared to the complication rates of open surgery for ASD, which range from $40 \%$ to $86 \% .{ }^{34}$ In addition, it was observed that the mean surgical time for the previous procedure is estimated at 4 hours and for the posterior procedure, around 3.9 hours, with low blood loss estimated at $2.1 \mathrm{~L}$, and an average hospitalization time of 20.7 days. Thus, MIS is more effective than open surgery, and consequently improves the patient's clinical condition. ${ }^{35}$

\section{Cost-Utility of Surgery for Adult Scoliosis}

Per capita health costs in the United States have increased considerably over the years, consuming around $17 \%$ of the gross domestic product in 2013 compared to 13\% in 2000. This increase is closely linked to advances in technology, which have increased the efficiency of procedures in general. ${ }^{36}$ Teles et al. presented a data set of patients with spinal deformity. ${ }^{6}$ The prevalence of adults with scoliosis ranges from $1.4 \%$ to $32 \%$ in the general US population, and $68 \%$ in the elderly population. Over the past decade, the costs of ASD treatment have increased more than 16-fold, from US\$56 million to US\$958 million. Individual costs, including complications and surgical revisions, are US\$269,807 and US\$391,889 for MIS and open surgery, respectively. ${ }^{37}$ The cost of revision surgery is a noteworthy factor in relation to Proximal Junctional Failure (PJF) following thoracolumbar fusion in ASD. It is estimated that about US\$55,547 is directly spent on surgical reintervention per patient. ${ }^{38}$

A comparison of conservative treatment versus surgical treatment shows cost differences. Conservative treatment costs US $\$ 14,022$, while the cost of surgical intervention is higher, around US\$ 35,897 for spinal decompression alone. ${ }^{39}$ Surgical treatment of ASD is cost effective, presenting a significant improvement in pain for a period of time. Despite having a higher cost, the surgical approach in ASD gives a better prognosis for these patients. ${ }^{40}$ The increase in patients with a primary diagnosis of deformity increased from 675,470 in 2000 to 813,849 in 2010 corresponding to a $20 \%$ increase. Moreover, rising costs quadrupled over the same period, from US\$344 million to US\$1.7 billion. As a result of this increase, an investigation into the costs of conservative treatment found that the average cost, after two years, is US\$10,815. In relation to the degree of symptoms, the specific average was US\$9,704 for patients who presented few symptoms, US\$11,116 for those with an average number of symptoms, and US\$14,022 for those with a greater number of symptoms. This is different from the costs involved in surgery, which in adolescents with idiopathic scoliosis, is US\$32,836. However, it is not possible to determine how many patients will require surgical treatment, since the surgical approaches reduce the symptoms almost immediately, compared to non-invasive treatment, leading to a significant gain in ASD patients' quality of life. ${ }^{41}$

A statistical analysis conducted in recent years has shown that hospital costs on the surgical treatment of patients with ASD have increased considerably. Over a 5-year period the average cost was US\$103,143 for the first year, US\$111,807 for the second year, US\$115,190 for the third year, US\$121,229 for the fourth year, and US\$126,323 for the fifth year. Surgery represents the highest cost of hospitals, around $59 \% .{ }^{42}$ ASD surgery is performed for a variety of reasons. Categorization of the diagnosis allows us to predict and analyze the surgical cost. The patient's age and comorbidities and the severity of the disease are variables that influence the surgical decision. However, the cost of medical treatment is still a critical component in the choice of intervention technique. ${ }^{43}$ Therefore, ASD patients benefit more from surgical treatment than from conservative treatment. This is because despite its lower cost, non-invasive treatment does not have a positive impact in terms of improving patients' quality of life, since this type of intervention does not give a better prognosis, and surgery is necessary to reduce the pain. ${ }^{44}$

\section{Shared-Decision Making in Adult Spinal Deformity}

Surgical decision-making in patients with ASD is a complex process that has recently raised ethical considerations. The reasons against the surgical approach are related to the fact that approximately $68 \%$ of individuals over 60 years old present some degree of deformity in the spine, and with population aging, this incidence will increase still further. Another factor that negatively affects the surgical approach are the complications, which range from $30 \%$ to $75 \%$, and the high mortality rate of $4 \% .{ }^{45}$ These data may discourage decision-making because they do not take into account the most important aspect, the patient's quality of life. Thus, the benefits associated with surgery far outweigh the risks and costs, because surgical intervention is aimed at correcting the defect, leading to better health and longer pain-free survival. ${ }^{46}$ Elderly patients (65-85 years) have a higher incidence of ASD, therefore they present greater disability, and more pain in the lower limbs compared to young people (25-44 years). However, it should be emphasized that elderly patients present a higher risk of complications than young patients. ${ }^{47}$

Interventions that can be addressed in patients with ASD involve the choice between conservative treatment or surgical treatment. The purposes of surgery include patient safety, decompression of neural elements, realignment of the spine, and lasting results, but it involves risks and costs. Although the cost of the intervention is greater compared to conservative treatment, the cost-benefit and quality-of-life gains are evident through the effective development of the surgical technique, which limits expenditure by reducing complications. ${ }^{48}$ Consent is extremely important, and favors decision-making between the patient and the doctor. This process helps the patient to be better prepared in terms of expectations of the surgical treatment and satisfaction with the outcome. In one study, it was observed that after explaining the risks involved in ASD surgery, only $45 \%$ of the information was retained by the patient immediately after the conversation. After one year, the level of retained information dropped to $18 \%$. It was observed that even after having had the risks of surgery explained to them, patients who presented complications as a result of the surgery demonstrated, during the interview with the doctor, great dissatisfaction with the surgery and 
with the surgeon. Therefore, the technique and the possible risks involved in the surgical treatment should be clearly discussed with the patient in advance. ${ }^{49}$

\section{CONCLUSIONS AND IMPLICATIONS FOR FUTURE RESEARCH}

Through a review of the literature published in the past five years, this study has shown that the benefits of surgical treatment in ASD far outweigh those of conservative treatment. Despite the potential complications, such as neurological deficit, the surgical approach substantially improves patients' levels of pain. The decision to perform invasive surgery in ASD demonstrates the effectiveness of the technique that has undergone continual advances, providing better remission of pain soon after the scoliosis correction procedure.
Improvement in the technologies used in the surgery, such as MIS and XLIF, minimally invasive techniques that promote well-being and patient safety, have led to a lower rate of complications. Despite presenting a higher cost than conservative treatment, surgery aims at the well-being of patients with spinal deformities, favoring a return to normal activities after the procedure. Therefore, further research is necessary, to gather data on patient safety, means of reducing the cost of surgical techniques, and techniques to reduce postoperative complications.

All authors declare no potential conflict of interest related to this article.

CONTRIBUTION OF THE AUTHORS: Each author made significant individual contributions to this manuscript. JD $(0000-0001-7364-7065)^{*}$ and ART $(0000-0003-2169-8156)^{\star}$ were the main contributors in the preparation of the manuscript. JD $(0000-0001-7364-7065)^{\star}$, ART (0000-0003-2169-8156) and AF (0000-0002-0016-3198)* carried out the bibliographic research and revision of the manuscript, and contributed to the intellectual concept of the study. ${ }^{*} \mathrm{ORCID}$ (Open Researcher and Contributor ID).

\section{REFERENCES}

1. Fehlings MG, Tetreault $L$, Nater A, et al. The Aging of the Global Population: The Changing Epidemiology of Disease and Spinal Disorders. Neurosurgery. 2015;77/Suppl 4):S1-5.

2. Bess S, Line B, Fu KM, McCarthy I, Lafage V, Schwab F, et al. The Health Impact of Symptomatic Adult Spinal Deformity: Comparison of Deformity Types to United States Population Norms and Chronic Diseases. Spine (Phila Pa 1976). 2016;41(3):224-33.

3. Ailon T, Smith JS, Shaffrey Cl, Lenke LG, Brodke D, Harrop JS, et al. Degenerative Spinal Deformity. Neurosurgery. 2015;77(Suppl 4):S75-91.

4. Pellise $F$, Vila-Casademunt $A$, Ferrer $M$, Domingo-Sàbat $M$, Bagó J, Pérez-GruesoFJ, et al. Impact on health related quality of life of adult spinal deformity (ASD) compared with other chronic conditions. Eur Spine J. 2015;24(1):3-11.

5. Youssef JA, Orndorff DO, Patty CA, Scott MA, Price HL, Hamlin LF, et al. Current status of adult spinal deformity. Global Spine J. 2013;3(1):51-62.

6. Teles AR, Mattei TA, Righesso O, Falavigna A. Effectiveness of Surgery and Nonoperative Care for Adult Spinal Deformity: Systematic Review of the Literature. Global Spine J. 2017;7(2):170-8

7. Scheer JK, Smith JS, Clark AJ, Lafage V, Kim HJ, Rolston JD, et al. Comprehensive study of back and leg pain improvements after adult spinal deformity surgery: analysis of 421 patients with 2-year follow-up and of the impact of the surgery on treatment satisfaction. J Neurosurg Spine. 2015;22(5):540-53.

8. Smith JS, Shaffrey Cl, Lafage V, Schwab F, Scheer JK, Protopsaltis T, et al. Com parison of best versus worst clinical outcomes for adult spinal deformity surgery: a retrospective review of a prospectively collected, multicenter database with 2-year follow-up. J Neurosurg Spine. 2015;23(3):349-59.

9. Gum JL, Hostin R, Robinson C, Kelly MP, Carreon LY, Polly DW, et al. Impact of cost valuation on cost-effectiveness in adult spine deformity surgery. Spine J. 2016;17(1):96-101.

10. Smith JS, Lafage V, Shaffrey $\mathrm{Cl}$, Schwab F, Lafage R, Hostin R, et al. Outcomes of Operative and Nonoperative Treatment for Adult Spinal Deformity: A Prospective, Multicenter, Propensity-Matched Cohort Assessment With Minimum 2-Year Follow-up. Neurosurgery. 2016;78(6):851-61.

11. Smith JS, Shaffrey Cl, Glassman SD, Carreon Ly, Schwab FJ, Lafage V, et al. Clinical and radiographic parameters that distinguish between the best and worst outcomes of scoliosis surgery for adults. Eur Spine J. 2013;22(2):402-10

12. Mannion AF, Vila-Casademunt $A$, Domingo-Sabat $M$, Wunderlin $S$, Pellisé $F$, Bago $\mathrm{J}$, et al. The Core Outcome Measures Index (COMI) is a responsive instrument for assessing the outcome of treatment for adult spinal deformity. Eur Spine J. 2016;25(8):2638-48

13. Soroceanu A, Burton DC, Oren JH, Smith JS, Hostin R, Shaffrey $\mathrm{Cl}$, et al. Medica Complications after Adult Spinal Deformity Surgery: Incidence, Risk factors, and Clinical Impact. Spine (Phila Pa 1976). 2016;41(22):1718-23.

14. Manoharan SR, Baker DK, Pasara SM, Ponce B, Deinlein D, Theiss SM. Thirty-day readmissions following adult spinal deformity surgery: an analysis of the National Surgical Quality Improvement Program (NSOIP) database. Spine J. 2016;16(7):862-6.

15. Passias PG, Soroceanu A, Yang S, Schwab F, Ames C, Boniello A, et al. Predictors of Revision Surgical Procedure Excluding Wound Complications in Adult Spinal Deformity and Impact on Patient-Reported Outcomes and Satisfaction: A Two-Year Follow-up. J Bone Joint Surg Am. 2016;98(7):536-43.

16. Smith JS, Klineberg $\mathrm{E}$, Lafage $\mathrm{V}$, Shaffrey $\mathrm{Cl}$, Schwab F, Lafage $\mathrm{R}$, et al. Prospective multicenter assessment of perioperative and minimum 2-year postoperative complication rates associated with adult spinal deformity surgery. J Neurosurg Spine. 2016;25(1):1-14

17. Klineberg EO, Passias PG, Jalai CM, Worley N, Sciubba DM, Burton DC, et al. Predicting Extended Length of Hospital Stay in an Adult Spinal Deformity Surgical Population. Spine (Phila Pa 1976). 2016;41(13):E798-805

18. Soroceanu A, Diebo BG, Burton D, Smith JS, Deviren V, Shaffrey C, et al. Radiographical and Implant-Related Complications in Adult Spinal Deformity Surgery: Incidence, Patient Risk Factors, and Impact on Health-Related Quality of Life. Spine (Phila Pa 1976). 2015;40(18):1414-21.

19. La Maida GA, Luceri F, Gallozzi F, Ferraro M, Bernardo M. Complication rate in adult deformity surgical treatment: safety of the posterior osteotomies. Eur Spine J. 2015;24(Suppl 7):879-86

20. Charosky S, Guigui P, Blamoutier A, Roussouly P, Chopin D, Study Group on S. Complications and risk factors of primary adult scoliosis surgery: a multicenter study of 306 patients. Spine (Phila Pa 1976). 2012:37(8):693-700

21. Lenke LG, Fehlings MG, Shaffrey $\mathrm{Cl}$, Cheung KM, Carreon $\mathrm{L}$, Dekutoski MB, et al Neurologic Outcomes of Complex Adult Spinal Deformity Surgery: Results of the Prospective, Multicenter Scoli-RISK-1 Study. Spine (Phila Pa 1976). 2016;41(3):204-12.

22. Kim HJ, Iyer S, Zebala LP, et al. Perioperative Neurologic Complications in Adult Spinal Deformity Surgery: Incidence and Risk factors in 564 Patients. Spine (Phila Pa 1976). 2017:42(6):420-7

23. lorio JA, Reid P, Kim HJ. Neurological complications in adult spinal deformity surgery Curr Rev Musculoskelet Med. 2016;9(3):290-8.

24. Bach K, Ahmadian A, Deukmedjian A, Uribe JS. Minimally invasive surgical techniques in adult degenerative spinal deformity: a systematic review. Clin Orthop Relat Res. 2014:472(6):1749-61

25. Kanter AS, Tempel ZJ, Ozpinar A, Okonkwo DO. A Review of Minimally Invasive Procedures for the Treatment of Adult Spinal Deformity. Spine (Phila Pa 1976). 2016;41(Suppl 8):S59-65.

26. Park P, Okonkwo DO, Nguyen S, Mundis GM Jr, Than KD, Deviren V, et al. Can a Minimal Clinically Important Difference Be Achieved in Elderly Patients with Adult Spinal Deformity Who Undergo Minimally Invasive Spinal Surgery? World Neurosurg. 2016;86:168-72

27. Than KD, Park P, Fu KM, Nguyen S, Wang MY, et al. Clinical and radiographic parameters associated with best versus worst clinical outcomes in minimally invasive spinal deformity surgery. J Neurosurg Spine. 2016;25(1):21-5.

28. Park P, Wang MY, Lafage V, Nguyen S, Ziewacz J, Okonkwo DO, et al. Comparison of two minimally invasive surgery strategies to treat adult spinal deformity. J Neurosurg Spine. 2015;22(4):374-80.

29. Strom RG, Bae J, Mizutani J, Valone F 3rd, Ames CP, Deviren V. Lateral interbody fusion combined with open posterior surgery for adult spinal deformity. J Neurosurg Spine. 2016:25(6):697-705.

30. Mummaneni PV, Park P, Fu KM, Wang MY, Nguyen S, Lafage V, et al. Does Minimally Invasive Percutaneous Posterior Instrumentation Reduce Risk of Proximal Junctional Kyphosis in Adult Spinal Deformity Surgery? A Propensity-Matched Cohort Analysis. Neurosurgery. 2016;78(1):101-8.

31. Berjano P, Lamartina C. Far lateral approaches (XLIF) in adult scoliosis. Eur Spine J. 2013;22(Suppl 2):S242-53.

32. Mummaneni PV, Shaffrey Cl, Lenke LG, Park P, Wang MY, La Marca F, et al. The minimally invasive spinal deformity surgery algorithm: a reproducible rational framework 
for decision making in minimally invasive spinal deformity surgery. Neurosurg Focus. 2014;36(5):E6.

33. Dangelmajer S, Zadnik PL, Rodriguez ST, Gokaslan ZL, Sciubba DM. Minimally invasive spine surgery for adult degenerative lumbar scoliosis. Neurosurg Focus. 2014;36(5):E7.

34. Anand N, Baron EM, Khandehroo B, Kahwaty S. Long-term 2- to 5-year clinical and functional outcomes of minimally invasive surgery for adult scoliosis. Spine (Phila Pa 1976). 2013:38(18):1566-75.

35. Anand N, Baron EM, Kahwaty S. Evidence basis/outcomes in minimally invasive spinal scoliosis surgery. Neurosurg Clin N Am. 2014;25(2):361-75.

36. Hostin R, Robinson C, O'Brien M, Ames C, Schwab F, Smith JS, et al. A Multicenter Comparison of Inpatient Resource Use for Adult Spinal Deformity Surgery. Spine (Phila Pa 1976). 2016;41(7):603-9.

37. Uddin OM, Haque R, Sugrue PA, Ahmed YM, El Ahmadieh, Press JM, et al. Cost minimization in treatment of adult degenerative scoliosis. J Neurosurg Spine. 2015;23(6):798-806

38. Theologis AA, Miller L, Callahan M, et al. Economic Impact of Revision Surgery for Proximal Junctional Failure After Adult Spinal Deformity Surgery: A Cost Analysis of 57 Operations in a 10-year Experience at a Major Deformity Center. Spine (Phila Pa 1976). 2016;41(16):E964-72.

39. Shaffrey $\mathrm{Cl}$, Smith JS. Editorial: Incremental cost-effectiveness of adult spinal deformity surgery. Neurosurg Focus. 2014;36(5):E4.

40. McCarthy I, O'Brien M, Ames C, Robinson C, Errico T, Polly DW Jr, et al. Incremental cost-effectiveness of adult spinal deformity surgery: observed quality-adjusted life years with surgery compared with predicted quality-adjusted life years without surgery. Neurosurg Focus 2014;36(5):E3.
41. McCarthy I, Hostin R, O'Brien M, Saigal R, Ames CP. Health economic analysis of adult deformity surgery. Neurosurg Clin N Am. 2013;24(2):293-304.

42. McCarthy IM, Hostin RA, Ames CP, Kim HJ, Smith JS, Boachie-Adjei O, et al. Total hospital costs of surgical treatment for adult spinal deformity: an extended follow-up study. Spine J. 2014;14(10):2326-33.

43. McCarthy IM, Hostin RA, O'Brien MF, Fleming NS, Ogola G, Kudyakov R, et al. Analysis of the direct cost of surgery for four diagnostic categories of adult spinal deformity. Spine J. 2013;13(12):1843-8

44. Paulus MC, Kalantar SB, Radcliff K. Cost and value of spinal deformity surgery. Spine (Phila Pa 1976). 2014;39(5):388-93.

45. Berven SH, Hohenstein NA, Savage JW, Tribus CB. Does the Outcome of Adult Deformity Surgery Justify the Complications in Elderly (Above 70 y of Age) Patients? J Spinal Disord Tech. 2015;28(8):271-4.

46. cheer JK, Lafage V, Smith JS, Daviren V, Hostin R, McCarthy IM, et al. Impact of age on the likelihood of reaching a minimum clinically important difference in 374 threecolumn spinal osteotomies: clinical article. J Neurosurg Spine. 2014;20(3):306-12.

47. Smith JS, Shaffrey Cl, Glassman SD, Berven SH, Shwab FJ, Hamil CL, et al. Risk-benefit assessment of surgery for adult scoliosis: an analysis based on patient age. Spine (Phila Pa 1976). 2011;36(10):817-24.

48. Gussous Y, Than K, Mummaneni P, Smith J, Steinmetz M, Ohya J, et al. Appropriate Use of Limited Interventions vs Extensive Surgery in the Elderly Patient With Spinal Disorders. Neurosurgery. 2015;77(Suppl 4):S142-63.

49. Saigal R, Clark AJ, Scheer JK, Smith JS, Bess S, Mummameni PV, et al. Adult Spinal Deformity Patients Recall Fewer Than $50 \%$ of the Risks Discussed in the Informed Consent Process Preoperatively and the Recall Rate Worsens Significantly in the Postoperative Period. Spine (Phila Pa 1976). 2015;40(14):1079-85. 